\title{
Strategic Plans of Faculty Management for Developing Universities Participated in Double-First Class Construction Program
}

\author{
Shen Sun * \\ Faculty of Environment and Life, Beijing University of Technology, Beijing, China, 100124 \\ ${ }^{*}$ Corresponding author Email: sunshen@jbut.edu.cn
}

\begin{abstract}
Based on SWOT analysis, strategic plans of faculty management are proposed for developing universities who are the finalists of double-first class university construction program ran by Chinese government. The strategic plans aim to accelerate the targeted universities to get developed at a rapid pace continuously, and to build up a competitive faculty cohort from the aspects of recruitment, assessment, management and diversity. By learning three top universities in US, a Tenure Track based system was proposed in complementation with secured positions of full-time designed lecturers. Diversity is emphasized in construction of faculty cohorts and state-of-art technologies are suggested to be applied to faculty management.
\end{abstract}

Keywords: Faculty management, Tenure track, Double first class, SWOT, High education.

\section{INTRODUCTION}

This paper proposes strategic plans of faculty management for the universities in China who are stepping towards double-first class universities in the world. The SWOT analysis is performed to illustrates the strength, weaknesses, opportunities and threats. Three top universities which are Harvard University, Massachusetts Institute of Technology (MIT) and Northwestern University in US were reviewed to make the comparison in aspect of Tenure Track, recruitment and faculty development. Disadvantages and challenges were concluded and expected to be figured out by learning through the examined three universities. The strategy of faculty management is, therefore, formed through the investigation.

The SWOT analysis is presented in section 2, followed by the proposal of strategic plans in section 3 . Section 4 is a discussion part, and this paper is ended with summary in section 5 .

\section{SWOT ANALYSIS}

It is well known that faculty plays a key role in universities. The more talent and professional faculties are, the higher rank universities achieves. Consequently, a proper strategic plan of faculty management makes significant contribution to university development. This is particularly the case of developing universities in China who were selected to participate in the country's construction plan of world-class universities and firstclass disciplines [1]. Some local universities have been making continuous efforts to achieve the goal step by step. For example, Beijing University of Technology (BJUT) announced a plan of becoming a double-first class university within 3 steps. It is becoming a world class university on 2020, and then initially launch its first-class university on 2030. By 2060, the year of 100th anniversary, ranking among first-class university with multiple first-class disciplines will be fulfilled eventually.

To achieve this, a series of advanced strategies are, therefore, desired to be performed sustainably in the following years. Strategy of faculty management is, without any doubts, the most important for university development. However, it is necessary to make such strategies in accordance with current status which can be indicated by SWOT analysis. As illustrated in Fig. 1, chart of SWOT analysis, there are strengths, weaknesses, opportunities and threats composing SWOT analysis. 


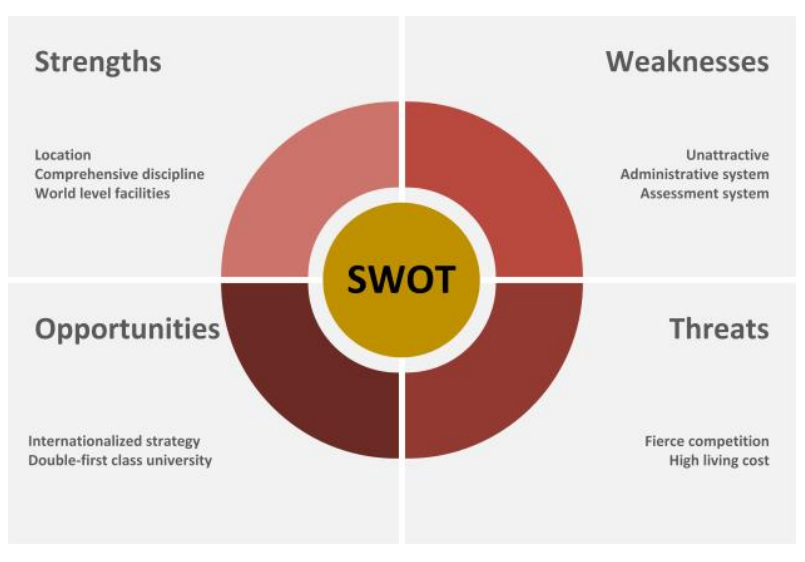

Figure 1 Chart of SWOT analysis

\subsection{Strengths}

Location is one of the most influential factors on which development of universities is dependent. Most targeted universities are located in the cities possessing intensive resources like Beijing, Shanghai and Guangzhou, the biggest cities in China. This means the exist of thousands of talents and a huge demand from industry and market. This is the most powerful strength of having huge potentials for establishing a talent faculty cohort. Consequently, research and education can be benefit and accelerated.

Another advantage is that most of the selected universities possess comprehensive disciplines and world-class facilities which laid a solid foundation for future development.

\subsection{Weaknesses}

Nevertheless, challenges are still crucial as most universities is less attractive in comparison to worldclass institutes. As a result, it is hard to recruit top specialists around the world.

Another concern is the incompliant administrative system and assessment system, which means universities, could be operated more effectively.

\subsection{Opportunities}

As China is constructing world-class universities, great efforts have been being putted on deepening reform and strengthening collaborations internationally. And this became an important strategy for developing universities in China. As globalization and internationalization are getting wilder and deeper, more opportunities arise. Moreover, along with the government launching the program of double-first class university construction, more resources and supports will be guided to be putted into these universities. These supports from government will be durable and sustainable.

\subsection{Threats}

Although there are quite a lot of opportunities for targeted universities, threats are serious as well. Firstly, it is dramatically costy to live in such a world-class city, resulting heavy economic burdens for both scholars and university. A threat arise as low wages and benefits are unattractive, on the contrary high salary results low effectiveness in current system. Secondly, in China, colleges, institutes and universities are highly concentrated. This results fierce competition that seriously increases the gap between developed universities and universities in development. As a result, these developing universities having high stresses are facing significant threats from those competitors occupying more resources.

\section{STRATEGIC PLANS}

To make a proper strategy of faculty management that accelerate development, this kind of universities should exploit strengths and avoid weaknesses, that captures opportunities and overcomes threats. A strategic plan is then proposed according to the SWOT analysis.

An important rule of making a such strategy is to fully utilizing strengths. As these universities located at resources-highly-concentrated cities, they should work closely with local government to attract more talents, and utilize rich resources in big city to increase faculty's welfare including offspring education, usages of public facilities, experiences of diverse cultures and opportunities of continuing education.

A comprehensive assessment system should be established along with a compliant reward and punishment system. With such an efficient system, faculties could be motivated and inspired. Meanwhile, potential is able to be analyzed by tracing their performance. Tenure Track system wildly applied in US high education institutes seems like a solution. Typically, the Tenure Track grants a professor profitable position at beginning and shows the professional pathway to promotion and academic job security for permanent employment in life-long career. This provides both economic freedoms and academic freedoms that get faculties inspired and cultivated. It reports that applicants who are seeking for an academic job are willing to seek any additional means to increase the chances of securing position, essentially during the transition from doctoral students to assistant professors [2]. However, from an investigation of Northwestern University, the conclusion was given as students learn relatively more from contingent faculty in their firstterm courses [3]. Therefore, full-time designated teachers could be in compensation to Tenure Track/Tenure system. 
Nowadays, local universities are getting more internationalized, and more efforts have been made for globalization. In this process, faculty diversity is recognized as an important rule for recruitment strategy. Diversity is the motivation of innovation. Top universities like Harvard University have been engaging more diversity in faculty recruitments. The demographics of faculty in Harvard University is indicated in Fig. 2. It is clearly shown that the faculty cohorts keep being diverse at a rapid pace $(\sim 12 \%)$ from 2005 to 2020.

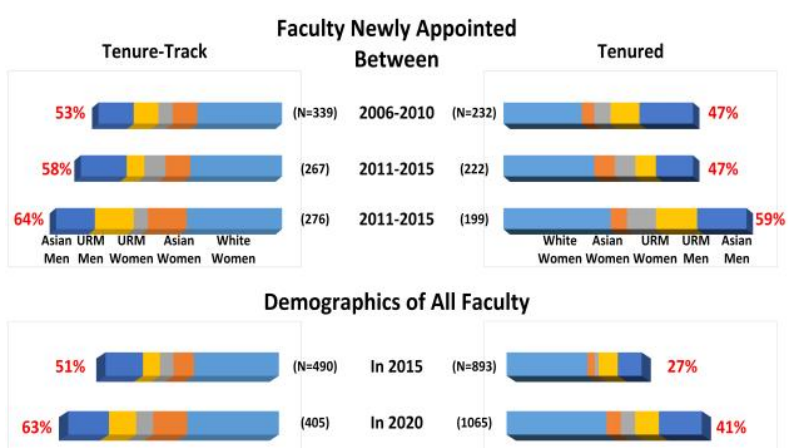

Figure 2 Demographics of faculty Cohorts, 2005-2020, Harvard University [4]

Although there are numbers of faculties having abroad-education background in local universities, (e.g., in BJUT $23.74 \%$ faculties possess over 1-year oversea experience), foreign faculties are in low proportion (104 in BJUT) [5]. To build world class university, global recruitment and diversely construction of faculty cohorts should be in consideration.

Collaborations among local universities take great opportunities to exchange ideas and talents. This can be applied to faculty training and fostering as well. International collaborations like scholar visitor programs, oversea training courses make progress on research and teaching. Domestic joint programs enhance communications, having great impact on personal development of faculty. In Boston, there are quite a lot of joint programs running by Harvard University and MIT. These include student exchange and academy exchange. For example, both universities open some courses to students in guest university. In some colleges, professors are allowed to give lectures and to have short-term exchange in guest university. This promotes academic communication and research cooperation. The targeted local universities possess plenty of resources of talents, education and trainings. Consequently, strengthening faculty training collaboration with fraternal institutes could be a feasible catalyst of faculty growth and development.

Construction of first-class disciplines is emphasized in program of double-first class university construction. The government encourages local universities to make progress on leading disciplines, exploring a differentiated development path. Based on this, structing a complete faculty cohort with Pyramid shape and introducing flexible growth pathway for faculty on both teaching and research creates differentiations. As a result, fierce competitions can be partially avoided.

\section{DISCUSSION}

In above analysis, statues of the targeted universities are elaborated from the aspects of strengths, weaknesses, threats and opportunities. Accordingly, faculty management strategic plans are worked out to fulfill the goals of construction of double-first class university. Undoubtedly, a suitable strategy can make sustainable development. Application of state-of-art technologies can promote development in an efficient way. For example, informatization technology can be applied to build up an informatic system that implement assessment, evaluation and management of faculty. To build a such system, cloud computing, big data and multi-structed database should be adopted to make this system efficient, flexible and scalable. With a such powerful system, data including teaching files, research deliverables, record on administrative activities, etc. can be stored and analyzed in cloud platform, enabling performance assessment, retrieving and prediction. Furthermore, automatic management/assessment can be operated by modeling under specified criteria. Therefore, strategies can be implemented efficiently.

A significant advantage of utilizing a such information system is that amount of data can be collected and recorded with time passing by. Therefore, dynamic analysis can be performed by comparing these data both vertically and parallelly. For example, when performing parallel comparison, it is possible to distinguish better outcomes between Tenure Track position and non-tenured designed position from aspect of teaching. By tracing back historical data (vertical comparison), it is quite straightforward to check if there is an improvement under current policy. Consequently, universities are capable to make adjustment and modification on the strategies in operation by examining these data in time, enabling dynamic analysis on strategy.

As more data collected, big data and Artificial Intelligent (AI) technologies can be applied to optimize the strategies and make universities run more efficiently.

\section{CONCLUSION}

This paper proposes strategic plans of faculty management for the universities that have been developing towards double-first class universities in China. An improved Tenure Track system is suggested in compensation with designed lectures. Strategy of building an internationalized faculty team is emphased 
by global recruitment for increasing diversity of faculty cohorts. Collaborations among local universities are welcomed from aspects of academic exchange and training programs. The series of strategies not only reduces the threats of fierce competition, the strengths of location having strong supports but also utilized maximally, enhancing universities' development.

\section{ACKNOWLEDGMENTS}

This work is supposed by 2020 UMD-BJUT Online Professional Development Program, and sponsored by Faculty Internationalization Training Program in Beijing University of Technology.

\section{REFERENCES}

[1] C. Wen-Bo, G. Rui, The Opportunities and Challenges of the Development of Higher Education Discipline by "Double First-Class"
Construction, Journal of Bingtuan Education Institute, 2017.

[2] M.C. Saffie-Robertson, J. Fiset, Finding a tenure-track position in academia in North America: Development of an employability model for new assistant professors, Higher Education Quarterly.

[3] D.N. Figlio, M.O. Schapiro, K.B. Soter, Are tenure track professors better teachers?, Review of Economics and Statistics, 97.4 (2015): 715-724.

[4] Faculty Development \& Diversity Annual Report 2020, Office of the Senior Vice Provost, Harvard University.

[5] Internationalization report of BJUT, 2020. 